$\begin{array}{cc}\text { Türk Coğrafya Dergisi } & \text { Turkish Geographical Review } \\ \text { Basıli ISSN 1302-5856 } & \text { ww.tcd.org.tr }\end{array}$

\title{
Malatya Fayı'nın morfometrik özellikleri
}

\section{Morphometric characteristics of the Malatya Fault}

\author{
Cengiz Zabcl *a \\ ${ }^{a}$ Istanbul Teknik Üniversitesi, Maden Fakültesi, Jeoloji Mühendisliği Bölümü, i̇stanbul
}

ORCID: C.Z. 0000-0003-0814-0422

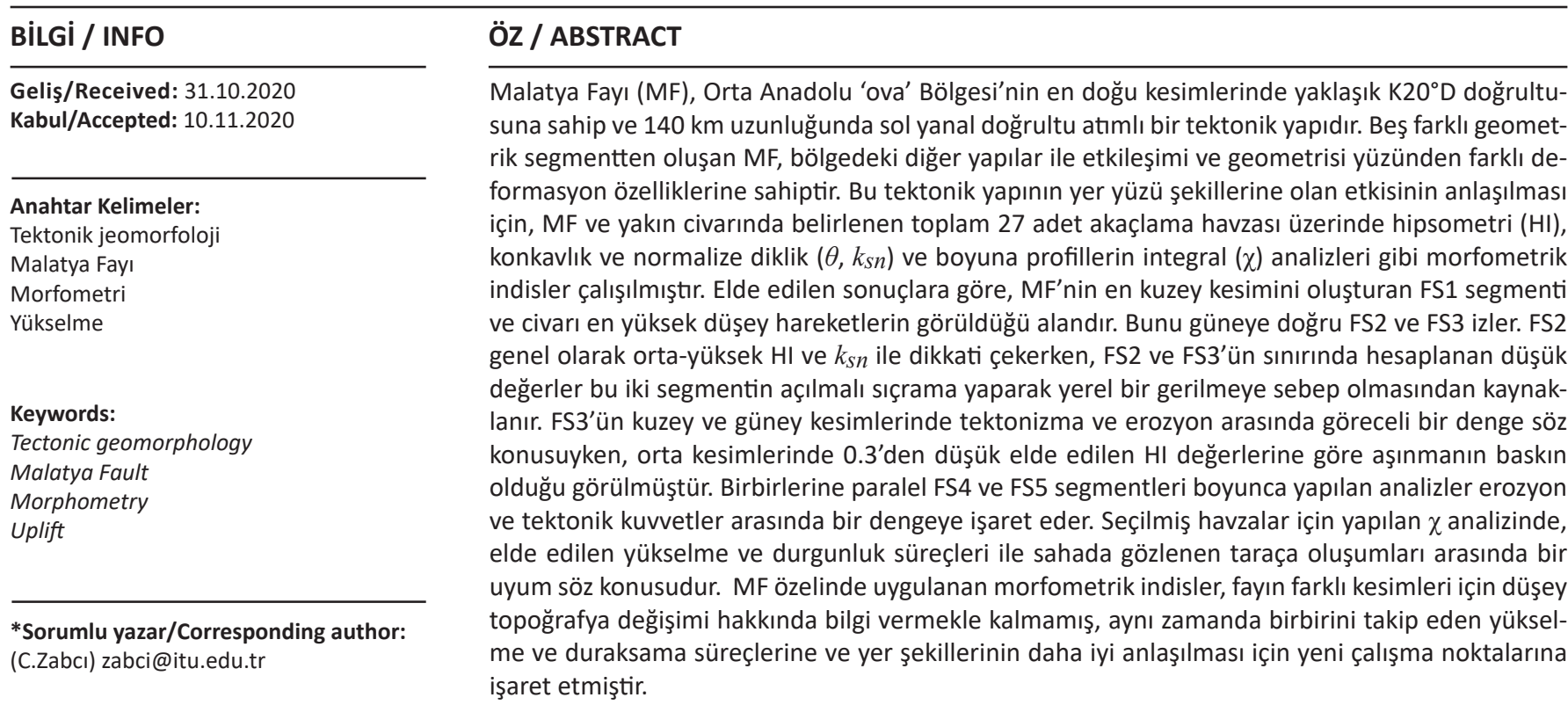

DOI: $10.17211 /$ tcd. 818850

\section{Atff/Citation:}

Zabcı, C. (2020). Malatya Fayı'nın morfometrik özellikleri. Türk Coğrafya Dergisi (75), 107-118

DOI: $10.17211 /$ tcd. 818850
Malatya Fault (MF) is a $140 \mathrm{~km}$-long sinistral structure, which strikes of about $\mathrm{N} 20^{\circ} \mathrm{E}$ in the most eastern parts the Central Anatolia 'ova' Province. The MF is made of five geometric segments that have distinct deformation properties. I defined a total of 27 drainage basins (HO1 to H27) along with this tectonic structure and applied the basic morphometric indices, such as hypsometry (HI), concavity and normalised steepness $\left(\theta, k_{s n}\right)$ and channel profile integral analyses $(\chi)$ to quantify the evolution of the landscape along the fault. The results of this study represent that the northernmost segment, FS1, and the surrounding region are strongly shaped under the effect of the vertical motions. Further to the south, the drainage basins the FS2 and FS3 relatively display moderate values, except the $\mathrm{H} 10$ that is located at the extensional step-over boundary between these two segments. Morphometric values suggest a balance between tectonics and erosion for the northern and southern sections of the FS3, whereas The HI values with lower than 0.3 suggest a dominant erosion for its central parts. My analyses along two sub-parallel segments, FS4 and FS5, also point a balance between erosional and tectonic forces with amoderate to low $\mathrm{HI}$ and $\mathrm{k}_{S n}$ values. In addition to quantification of the vertical motions, I tried to determine the successive uplifting and quiescence periods by using the channel profile integral analyses $(\chi)$. The estimated series of uplifting and quiescence periods well correlate with terrace formations, which are observed in the field. The study along the MF shows that morphometric analyses are important tools, particularly where there is none or limited field-based geomorphological and/or geological data. In this study, my results do not provide information only for the evolution of the landscape along the MF, but it also shows a potential for similar intra-plate settings in the earth. 
Extended Abstract Introduction

The face of the earth is mainly shaped by the interaction of two controlling factors; the internal and external processes. The struggle or balance between these two processes can be quantified by using various morphometric indices. Morphometric tools do not only give simple numbers, but they also provide important information on the relative effect of tectonic or erosional processes.

Malatya Fault (MF) and the landscape of the surrounding region is an ideal place where the relationship between these forces can be studied. This sinistral strike-slip fault is a member of a larger system, the Malatya-Ovacık Fault Zone (MOFZ), and is partly responsible for the internal deformation of Anatolia. Although earlier studies propose that the MOFZ and the MF were making the former eastern boundary of Anatolia, thus it is not an active structure anymore, recent structural, paleoseismology, tectonic geodesy, tectonic geomorphology, and seismology studies show remarkable activity along its entire length. The MF starts to the northwest of the Arapgir Town (Malatya) and prolongs of about $140 \mathrm{~km}$ with $\mathrm{N} 20^{\circ} \mathrm{E}$ strike to the south. This tectonic structure is classified into five segments (FS1-to-FS5) by using the geometry of its surface exposure trace. To the north, the MF makes the tectonic boundary between the Mesozoic limestones and ophiolitic melanges. It cuts Tertiary volcanics and Miocene-Pliocene siliciclastics around the Arguvan town (Malatya). Further to the south, it deforms various lithologies, including Eocene to Miocene classics and older marbles.

\section{Data and Methods}

I defined a total of 27 drainage basins ( $\mathrm{HO1}$ to $\mathrm{H} 27$ ) and extracted individual DEM files for each of them. Then, I used River Tools, TopoToolbox and LSDTopoTools to calculate the most common morphometric indices, such as the hypsometric curve and integral $(\mathrm{HI})$, concavity $(\theta)$ and normalised steepness $\left(k_{s n}\right)$, and channel profile integrals $(\chi)$, respectively, for these basins.

\section{Findings}

The HIs change between $0.2371(\mathrm{H} 21)$ and $0.6777(\mathrm{H} 3)$, among which the highest values belong to the northernmost basins ( $\mathrm{H} 1$ to $\mathrm{H} 6$ ) along the FS1. The high $k_{s n}$ of main rivers of these basins also provide additional evidence for tectonic uplift along this section of the MF. The FS2 and FS3 are characterized by moderate $\mathrm{HI}$ and $k_{S n}$ values except for $\mathrm{H} 10$ that is located exactly at the boundary of these two geometric segments. The $\mathrm{H} 10$ has relatively a lower $\mathrm{HI}$ and $k_{s n}$, which is most possibly due to the extension generated by the releasing step-over between the FS2 and FS3. Another exception is at the central part of the FS3, where the $\mathrm{H} 17$ and $\mathrm{H} 18$ have $\mathrm{HI}$ values of about 0.2 to 0.3 . Also, I picked two locations for further analyses, which are represented by the $\mathrm{H} 6,7$, and 8 at the boundary between the FS1 and FS2, and the H15, 16 and 18 at the central part of the FS3.

The $\chi$ analysis of the $\mathrm{H} 7$ shows evidence for a long period of continuous uplift, which is then replaced with a quiescence stage. The neighbouring basins, $\mathrm{H} 6$ and $\mathrm{H} 8$, starts with a similar continuous uplift in their history, but the $\mathrm{H} 8$ differs from $\mathrm{H} 6$ with a longer period of quiescence, whereas the limited number of $\mathrm{H6}$ 's channels continue to experience tectonic uplift in its later stage. At the central FS3, the $\mathrm{H} 15$ is characterized by a continuous uplift in its earliest stage, which is followed by a sequence of quiescence and re-uplifting. I observe the same also in the results of the integral analysis for the $\mathrm{H} 16$. The $\mathrm{H} 18$ is made of at least two upliftings and two quiescence periods, which is well supported by the terrace staircases of the Tohma River.

The most possible reason is the clockwise rotation of the MOFZ for the dominant vertical uplift of topography along the northernmost section of the MF (around FS1). Here, the MOFZ changes its strike from $N 65^{\circ}-70^{\circ} \mathrm{E}$ to $\mathrm{N} 20^{\circ} \mathrm{E}$, generating a wedge between its two distinct structural elements (The MF and the Ovacık Fault - OF). This wedge is mainly characterized by shortening, which is well supported by structural and geomorphological studies. The FS2 and FS3 relatively represent evidence for lower vertical motions. Nevertheless, especially $\chi$ analyses provide invaluable information on the development stages of topography and naturally the drainage network at these parts of the study region.

\section{Conclusion}

Morphometric analyses are important tools, particularly where there is none or limited field-based geomorphological and/ or geological data. Moreover, these indices can have a high contribution to the evaluation of a landscape, if they are combined with other techniques such as conventional mapping and Quaternary dating methods. In this study, my results do not provide information only for the evolution of the landscape along the MF, but it also shows potential for similar intra-plate settings in the earth.

\section{Giriş}

Dünyanın dış ve iç süreçleri arasındaki karşılıklı etkileşim ve denge, yer yüzünün zaman içerisinde şekillenmesini denetleyen en önemli unsurlardır (Whipple ve Tucker, 1999; Willett vd., 2006; Scotti vd., 2014). Akaçlama ağlarının analizi, bu değişim ve onun farklı aşamalarının belirlenmesinde birincil veri kaynaklarıdır (Keller ve Pinter, 1996; Molin vd., 2004; Pérez-Peña vd., 2009). Akaçlama sistemleri ve havzaları kullanılarak geliştirilen ve özellikle düşey değişimlere hassas jeomorfik indisler, tektonik etkinliğin olduğu bölgelerde yer şekillerine ait değişimin nicel olarak ifade edilmesini sağlar (Keller ve Pinter, 1996; Snyder vd., 2000; Kirby ve Whipple, 2001; Kirby vd., 2003, 2007; Clark vd., 2004; Schoenbohm vd., 2004; Burbank ve Anderson, 2011; Miller vd., 2012). Bu araçlar, yatay veya düşey deformasyonun görüldüğü farklı tektonik bölgelerin karakterize edilmesinin (ör: Chen vd., 2003; Pérez-Peña vd., 2010; Yıldırım, 2014; Whitney ve Hengesh, 2015; Sağlam Selçuk, 2016; Sançar, 2018; Yazıcı vd., 2018a; Topal, 2019a, 2019b) yanı sıra, dış süreçlerin yer yapılarını şekillendirmesi konusunda (ör: Williams, 1972; King, 1982; García-ruiz vd., 2000; Denizman, 2003; Öztürk, 2018; Çılğın ve Bayrakdar, 2020) önemli bilgiler verir. Günümüzde yaygın kullanım alanına sahip sayısal yükseklik modelleri (SYM), sundukları yüksek çözünürlüklü topoğrafya verisi ile morfometrik analiz uygulamalarını daha etkin hale getirmiştir (Bubenzer ve Bolten, 2008; Sreedevi vd., 2009; Pandey vd., 2017). 
Doğu Akdeniz'in karmaşık tektoniği içerisinde Anadolu'nun önemli aktif tektonik yapılarından biri olan Malatya Fayı (MF) ve yakın civarı, tektonik kuvvetlerin yüzey şekillerine etkisinin morfometrik indisler kullanılarak çalışılması için ideal yerlerden biridir (Şekil 1). Yaklaşık 140 km uzunluğa sahip bu tektonik yapı, sol yanal doğrultu atımlı bir karaktere sahiptir (Koçyiğit ve Beyhan, 1998; Westaway ve Arger, 2001; Kaymakçı vd., 2006; Westaway vd., 2008). Her ne kadar aktivitesi hakkında yoğun tartışmalar olsa da, son yıllarda bu fay üzerinde gerçekleştirilen paleosismoloji (Sançar vd., 2019), jeolojik kayma hızı (Sançar vd., 2020) ve sismoloji (Acarel vd., 2019) çalışmaları, MF'nin etkinliği ve deprem üretme potansiyeli hakkında önemli veriler sunmuştur. Bu çalışma, günümüzde süregelen bu aktif deformasyonun MF boyunca yüzey şekilleri üzerinde etkisini nicel olarak belirlemek için, hipsometri (HI), normalize diklik ve konkavlık $\left(\theta, k_{s n}\right)$ ve integral analizleri $(\chi)$ gibi temel morfometrik araçların bölge özelinde uygulamasından oluşur. Bu doğrultu atımlı fay sisteminde Anadolu Bloku'nun kinematiği ve fay geometrisinin etkisi ile kazandığı düşey deformasyon oranı ve bunun mekânsal değişimi hakkında bilgi veren bu analizler, sadece MF için değil, dünyada benzer levha içi kıtasal fayların davranış özellikleri hakkında öneme sahiptir.

\section{Tektonik Çerçeve ve Malatya Fayı}

2.1. Doğu Akdeniz ve Anadolu’nun Aktif Tektonik Çerçevesi

Doğu Akdeniz'in aktif tektoniği, Afrika, Arabistan ve Avrasya levhaları ile daha küçük olan Anadolu Bloku'nun birbirlerine göre gerçekleştirdikleri göreceli devinim ile şekillenir (McKenzie, 1972; Şengör, 1980; Şengör vd., 1985). Anadolu'nun Kuzey Anadolu (KAF) ve Doğu Anadolu (DAF) fayları boyunca Avrasya Levhası'na göre bat yönlü hareketinin nedeni olarak öne sürülen jeodinamik hipotezler, (a) Avrasya ve Arabistan levhalarının çarpışma sonrası devam eden birbirlerine yakınlaşma hareketi ve ikincil olarak Doğu Anadolu Yüksek Platosu'nun yerçekim potansiyel enerjisi ile desteklenen tektonik kaçma (McKenzie, 1972; Şengör vd. 1985; Özeren ve Holt, 2010; Şengör ve Yazıcı, 2020), (b) Helenik yayın çekme kuvveti (Armijo vd., 1999; Chorowicz vd., 1999; Reilinger vd., 2006), (c) astenosferde meydana gelen akımın litosferi sürüklemesi (Le Pichon ve Kreemer, 2010), (d) Afar manto sorgucuna bağlı olarak bütün mantoyu etkileyen Tetis konveksiyonel hücresinin etkisi (Faccenna vd., 2013) veya (e) bu mekanizmaların birleşimi (Paul vd., 2014; Philippon vd., 2014), başlıkları altında sınıflandırılabilir.

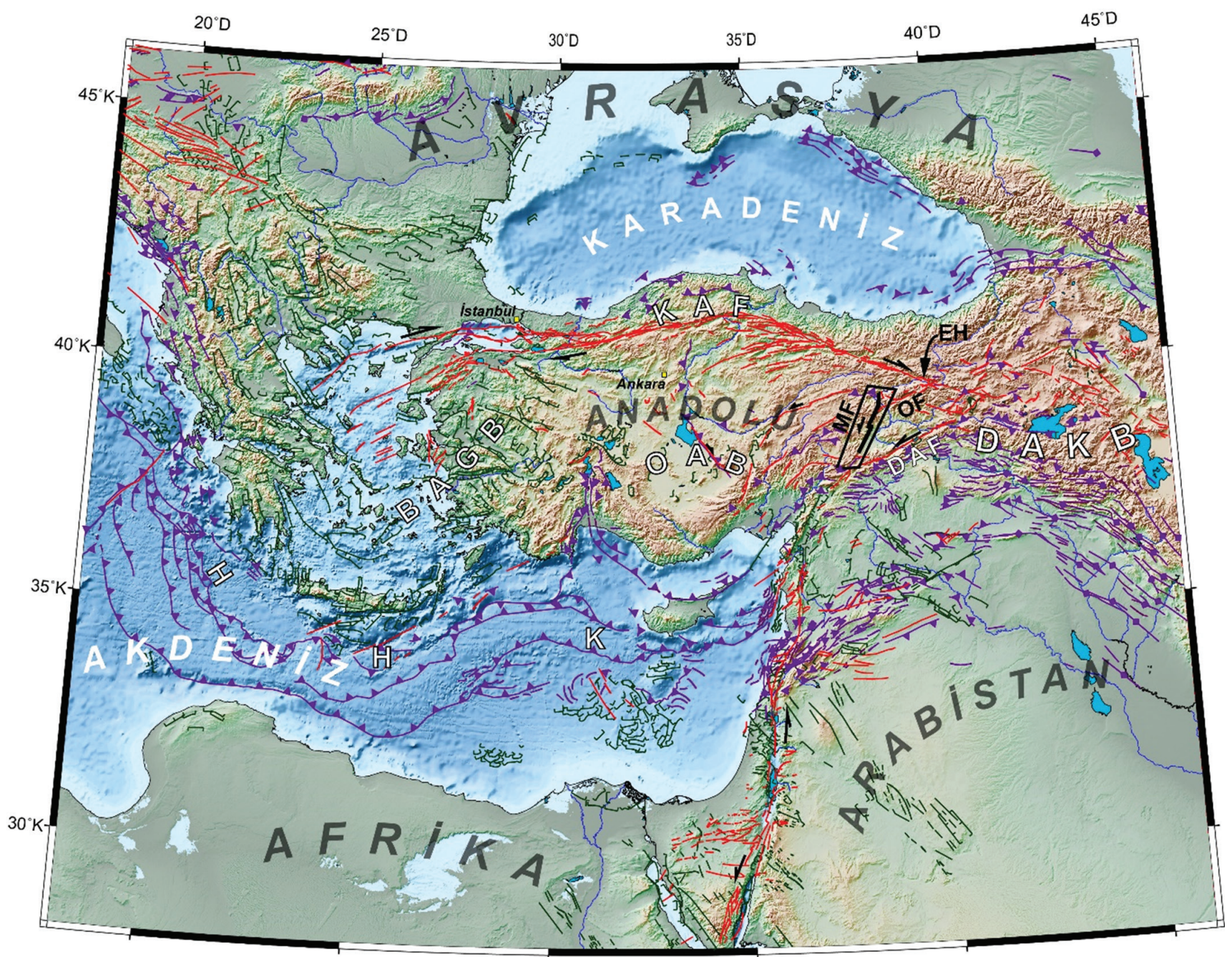

Şekil 1. Anadolu ve çevresinin orta-geç Miyosen'den ( 13-11 milyon yıl) günümüze bir zamanlar veya halen aktif olan neotektonik yapılar (Şengör ve Zabcı, 2019). Kırmızı renk doğrultu atımlı fayları, yeşil renk normal fayları ve mor renk sıkışmayla ilişkili bindirme ve kıvrımları göstermektedir. Kısaltmalar: $H$ - Helenik Yay, K - Kıbrıs Yayı, KAF - Kuzey Anadolu Fayı, DAF - Doğu Anadolu Fayı, BAGB - Bat Anadolu Gerilme Bölgesi, OAB - Orta Anadolu 'ova' Bölgesi, DAKB - Doğu Anadolu Kısalma Bölgesi, EH - Erzincan Havzası, OF - Ovacık Fayı. Malatya Fayı siyah renkle çizilmiş, çevre bölgesi ise siyah çerçeve ile işaretlenmiştir. Figure 1. Neotectonic structures of Anatolia and surrounding region, which are late medial Miocene ( 13 Ma) or younger (Şengör and Zabcl, 2019). Red lines are for strike-slip, green is for extensional, and purple is for compressional structures. The black line shows the Malatya Fault (MF), whereas black rectangle marks the surrounding region of the MF. H-Hellenic Arc, K-Cyprus Arc, KAF - North Anatolian Fault, DAF - East Anatolian Fault, BAGB - West Anatolian Extensional Province, OAB - Central Anatolia 'ova' Province, DAKB - East Anatolian Province of Shortening, EH - Erzincan Basin, OF - Ovacik Fault. 
Bu dinamik koşullara bağlı olarak meydana gelen deformasyon çeşitliliği, Anadolu'da dört neotektonik bölgenin oluşmasına yol açmıştır: (a) Doğu Anadolu Kısalma Bölgesi (DAKB), (b) Kuzey Türkiye Bölgesi (KTB), (c) Bat Anadolu Genişleme Bölgesi (BAGB) ve (d) Orta Anadolu 'ova' Bölgesi (OAB) (Şekil 1) (Şengör, 1980; Şengör vd. 1985; Şengör ve Yazıcı, 2020). DAKB, genelde kuzey-güney sıkışma rejimi altında oluşmuş doğu-bat doğrultulu bindirme, kuzeybatt-doğrultulu sağ yanal doğrultu atımlı faylar ve kuzeydoğu-doğrultulu sol yanal doğrultu atımlı faylarla karakterize olurken, BAGB kabaca doğu-bat doğrultulu normal fay - graben sistemleri ile dikkati çeker. KTB, göreceli Türkiye'nin sismik açıdan en sakin bölgesidir. Bu çalışmanın konusu olan Malatya Fayı'nın da yer aldığı OAB ise KTB'den sonra sismik olarak en suskun kesimdir (Şengör, 1980; Şengör vd., 1985). Bu bölgede plüvyal göl çökelleri neotektonik yapıların çoğunu örter (Şengör vd. 1985). Mevcut haritalanan aktif yapılar, genel olarak kuzeybat doğrultulu sağ yanal doğrultu atımlı faylar, kuzeydoğu doğrultulu sol yanal doğrultu atımlı faylar ile bunlara eşlik eden ikincil doğu-bat doğrultulu ters faylardan oluşur (yapıların genel bir özeti için lütfen Bozkurt, 2001'e bknz). Anadolu'nun sınırlarını oluşturan KAF ve DAF gibi büyük doğrultu atımlı faylara göre, bu yapıların çok daha düşük kayma hızına sahip oldukları ve seyrek deprem ürettikleri farklı çalışmalarda tespit edilmiştir (ör: Aktuğ vd. 2013; Akyüz vd., 2012; Higgins vd., 2015; Sarıkaya vd. 2015; Yıldırım vd., 2016; Zabcı vd. 2017; Yazıcı vd., 2018b; Sançar vd., 2019; Sançar vd. 2020).

\subsection{Malatya-Ovacık Fay Zonu ve Malatya Fayı}

Bu çalışmanın konusunu oluşturan MF, Orta Anadolu 'ova' neotektonik bölgesinin ana tektonik yapılarından Malatya-Ovacık Fay Zonu'nun (MOFZ) iki önemli unsurundan biridir (Şekil 2). KD'da Erzincan Havzası'ndan başlayan MOFZ, Arapgir batısına kadar kabaca $\mathrm{K} 65^{\circ}-70^{\circ} \mathrm{D}$ doğrultusunda $110 \mathrm{~km}$ boyunca uzanır. Bu noktada saat yönünde bir büklüm yapan fay kabaca kuzey-güney doğrultusunda güneyde Malatya'nın Doğanşehir ilçesine kadar $140 \mathrm{~km}$ boyunca devam eder (Şekil 1 ve 2) (Emre vd., 2013; Yazıcı vd., 2018a; Sançar vd., 2019). MOFZ'nin Erzincan Havzası ve Arapgir arasında kalan kısmı Ovacık Fayı (OF), Arapgir ve Doğanşehir arasında kalan kısmı ise MF olarak adlandırılmaktadır (Koçyiğit ve Beyhan, 1998; Westaway ve Arger, 2001). Çoğu çalışma MF ve OF'nin aynı sistem içinde yer aldığını öne sürüyor olsa da (Westaway ve Arger, 2001; Westaway vd., 2008), Kaymakçı vd. (2006) fayların kinematik özelliklerinin farklılığından dolayı bu iki yapıyı birbirinden ayırır. Sançar vd. (2019), geometrik özelliklerini gözeterek MF'yi toplam 5 segment altında sınıflandırmıştır (FS1-5; Şekil 2a).

MOFZ ve MF ile ilgili diğer bir tartışma konusu ise bu yapının günümüzdeki aktivitesi üzerinedir. Westaway ve Arger (2001) ve Westaway vd. (2008), MOFZ'nin Anadolu'nun eski doğu sınırı olduğunu, ancak günümüzde bu sınırın DAF ile temsil edildiğini öne sürerek, bu yapının arttk aktif olmadığını savunur. Ancak, OF ve MF üzerinde yapılan çok sayıda tektonik jeomorfoloji (Zabcı vd., 2017; Yazıcı vd., 2018a; Sançar vd., 2020), uzay jeodezisi (Özener vd., 2010; Aktuğ vd., 2013), paleosismoloji (Sançar vd., 2019; Yazıcı vd., 2018b), sismoloji (Acarel vd., 2019) ve yapısal jeoloji (Kaymakçı vd., 2006) tabanlı çalışma bunun aksine işaret eder. Bu çalışmalara göre günümüzde çok sayıda küçük ve orta ölçekli depremin meydana geldiği (Acarel vd., 2019) MF üzerinde, yüzey kırığı yaratan deprem- lerin olma sıklığı yaklaşık 2275 yıl (Sançar vd., 2019), fayın çok uzun dönem jeolojik kayma hızı ise $1 \mathrm{~mm} / \mathrm{yıl}$ olarak bulgulanmıştir (Sançar vd., 2020).

MF, en kuzey kesiminde kireçtaşları ile ofiyolitik melanj ve Miyosen karbonatları arasında tektonik dokanağı oluştururken, Arapgir güneybatısında Tersiyer yaşlı andezitik ve bazaltik volkanik kayaçları keser. Arguvan civarında, fay ve yakın civarında Tersiyer volkanikleri ve Miyosen-Pliyosen yaşlı çökel kayaçların yüzlekleri görülür. Güneye doğru MF, genelde fay kontrollü olarak gelişmiş Pliyosen ve Kuvaterner yaşlı kırıntılı ve az tutturulmuş birimlerle daha yaşlı çökel ve metamorfik kayaçlar arasında sınırı oluşturur (Bilgiç, 2002).

\section{Materyal ve Yöntemler}

MF'nin yer şekilleri üzerine etkisinin anlaşılması için bu çaIışmada hipsometrik eğri ve integral (HI), normalize diklik ve konkavlık $\left(k_{s n}, \theta\right)$ ve boyuna profillerin integral $(\chi)$ analizleri kullanılmıştır. Bu morfometrik indisler aracılığı ile topoğrafya üzerinde tektonizma ve iklimin ortak etkisinin nicel olarak belirlenmesi hedeflenmiştir.

Analizler 1:25000 ölçekli sayısal yükseklik paftalarının enterpolasyonu ile oluşturulmuş 15-m yer piksel çözünürlüğüne sahip SYM kullanılarak gerçekleştirilmiştir. Bu topoğrafya verisinden ilk olarak RiverTools yazılımının D-8 algoritması kullanılarak Strahler derecesi 3 ve üstü olan akaçlama kolları otomatik olarak çıkartıımıştır. İkinci adımda, MF boyunca belirlenen 27 adet akaçlama havzası için ayrı ayrı SYM'ler ArcGIS Desktop kullanılarak kesilerek hazırlanmıştır. Değişken boyutlara sahip bu havzaların fayın hem doğu hem de bat bloğu üzerinde yer aldığı görülür (Şekil 2a). Sonraki adımlarda morfometrik indislerin hesaplanmasında, RiverTools (hipsometrik eğri ve integral), Matlab tabanlı TopoToolbox (normalize diklik ve konkavlık; Schwanghart ve Scherler, 2014) ve LSDTopoTools (boyuna profillerin integral analizi; Mudd vd., 2014, 2018) yazılımları kullanılmıştır.

\subsection{Hipsometrik Eğri ve İntegral (HI)}

Akaçlama havzalarının alan ve yükseklik arasındaki oran hipsometrik eğriyi tanımlarken, yükseklik/alan dağılımı ile gösterilir (Strahler, 1952). Eğri, herhangi bir noktada alanın (a) toplam alana $(A)$ ve buranın yüksekliği $(h)$ ile havzanın en yüksek notası $(H)$ arasındaki oranlar kullanılarak oluşturulur. Çizilen bu eğrinin altında kalan alan ise hiprometrik integral (HI) değerini verir.

Bu eğrinin şekli ve $\mathrm{HI}$ morfolojinin olgunluk derecesine göre üç farklı sınıfa işaret eder: (a) dışbükey şekilli eğri ve HI'nın 0.5 'ten büyük olduğu, tektonik etkinin erozyona baskın geldiği, (b) S-şekilli eğri ve HI'nin 0.3 ila 0.5 arasında değer kazandığı, tektonik ve erozyon etkilerinin dengede olduğu ve (c) iç bükey şekilli eğriler ve HI'nın $0.3^{\prime}$ ten düşük olduğu erozyonun tektonik kuvvetlere baskın olduğu durumlar (Strahler, 1952; Keller ve Pinter, 1996; Walcott ve Summerfield, 2008).

Bu çalışmada, RiverTools 4 yazılımı kullanılarak, belirlenen her bir havza için ayrı ayrı HI değerleri hesaplanmıştır. Havzaların sahip olduğu HI değerleri, kendi aralarında deneştirilerek, MF boyunca düşey tektonik etkinin değişimi irdelenmiştir. 


\subsection{Diklik ve Konkavlık Analizleri $\left(k_{s n}, \theta\right)$}

Kanal boyu profillerin analizleri, tektonizma ve erozyon arasındaki dengenin anlaşılması için kullanılan diğer bir morfometrik araçttr. Tektonik kuvvetler ve erozyonun dengede olduğu flüvyal sistemlerde, akarsu yatağının yüksekliği sabit kalırken, boyuna profili düz ve iç bükey şekilli olur (Hack, 1973). Bu durum, yerel akım gradyanı ile akarsu boyu (Hack, 1957) veya yerel kanal eğimi ile akarsuyun kaynak alanı (Flint, 1974) arasında özel bir ilişki olduğuna işaret eder. Kanal profillerinin evrimi, ana kaya litolojisinin etkisi ve erozyon aşamaları, akarsuların eğim-alan ilişkileri kullanılarak tanımlanabilir (Whipple ve Tucker, 1999; Perron ve Royden, 2013). Bunlardan yola çıkarak kanal gradyanı ve kaynak alanı arasındaki uyumsuzluklar, aktif tektonizma ile açıklanabilir. Bu ampirik çalışmalara dayalı olarak yerel kanal gradyanı $(S)$ ve kaynak alanı $(A)$ arasında geçerli
“Güç Yasası” önerilmiştir (Flint, 1974).

$\mathrm{S}=k_{S n} A^{-\theta}$

1 no'lu denklemde yer alan $k_{s n}$ ve $\theta$ sırasıyla kanal dikliğini ve konkavlığını temsil eder (Whipple ve Tucker, 1999; Snyder vd., 2000; Kirby ve Whipple, 2001). Çok sayıda çalışma konkavlığın $(\theta)$ genelde 0.3 ila 0.7 arasında değerler taşıdığını göstermiştir (Whipple ve Tucker, 1999; Burbank ve Anderson, 2011). Kanal dikliği değeri $\left(k_{s n}\right)$ ise 1 no'lu denklemde akaçlama alanı için bir referans konkavlık değeri $\left(\theta_{\text {ref }}\right)$ kullanılarak hesaplanır (Wobus vd., 2006) ve özellikle tektonik etkinliğe işaret eder (Ouimet vd., 2009; Whittaker, 2012; Castillo vd., 2014; Sançar, 2018). MF boyunca normalize diklik ve konkavlık değerleri, Matlab üzerinden çalışan TopoToolbox yazılımı (Schwanghart and Kuhn, 2010; Schwangart ve Scherler, 2014) kullanılarak hesaplanmıştır.
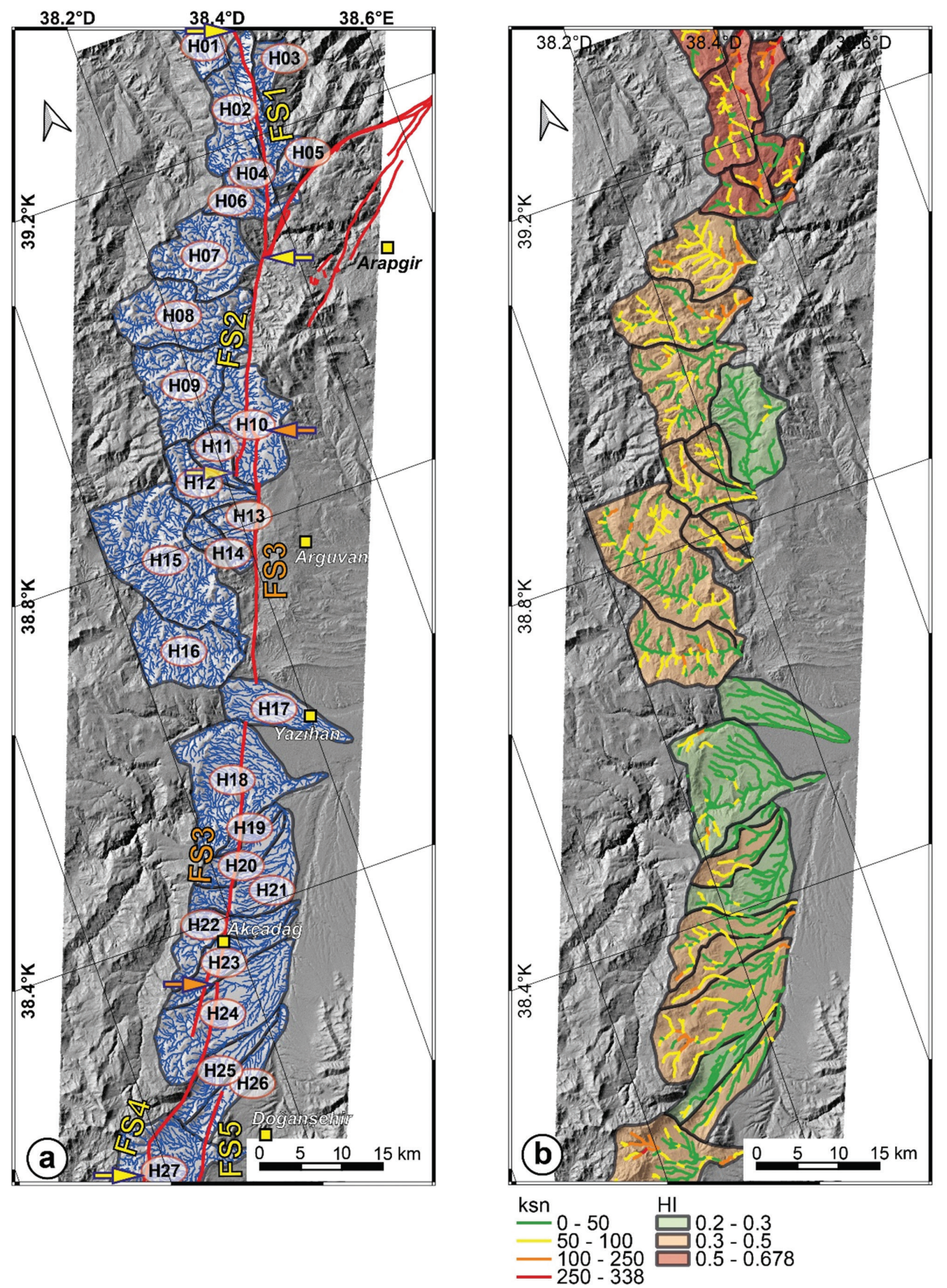

Şekil 2. (a) MF ve fay boyunca belirlenen akaçlama havzaları. Havzalar kuzeyden güneye doğru sırasıyla numaralandırılırken, MF'yi oluşturan segmentler FS kısaltması ile gösterilmiştir. Sarı ve turuncu oklar, segment sınırlarını işaretler. Faylar, Emre vd. (2013) ve Yazıcı vd. (2018a)'den alınmıştr. (b) Havzaların normalize edilmiş diklik $\left(k_{s n}\right)$ ve HI değerleri.

Figure 2. (a) The identified drainage basins along the Malatya Fault. Basins are numbered in an order from north to south. Geometric parts of faulting are labelled that starts with the abbreviation FS as for 'Fault Segment'. Yellow and orange arrows mark the segment boundaries. Faults are compiled from Emre et al. (2013) and YazıcI et al. (2018a). (b) Map showing the normalised steepness ( $\left.k_{s n}\right)$ and hypsometric integral (HI) values of drainage basins. 


\subsection{Boyuna Profillerinintegral Analizi $(\chi)$}

Ana kaya akarsularının eğim-alan analizine dayalı çalışmalar, özellikle SYM'lerin içerdiği hatalardan/eksikliklerden/çözünürlükten dolayı belli sınırlamalara sahiptir. Topoğrafya verisinin sahip olduğu bu kusurlar, eğim-alan grafiklerinin saçılmasına, dolayısıyla Güç Yasası'nın belirlenmesinde hatalara sebep olabilir. Özellikle SYM'lerde temel alındıkları topoğrafya haritasında eş yükselti eğrilerinin çözünürlüğüne bağlı olarak bahsedilen hatalar meydana gelebilir. Bu sorunu aşmak için Perron ve Royden (2013), kanal profillerinde yatay koordinatların $\chi$ (chi) denen bir değişkeninin integral dönüşümüne dayanan yeni bir yöntem önermişlerdir. $\chi$ değişkeni mesafe birimine sahiptir ve bir akaçlama alanında boyuna değişimleri gösterir. Kanal boyu yüksekliğin dönüştürülmüş bu boyuna değişim çizimlerine de chi-grafiği adı verilir (Perron ve Royden, 2013; Mudd vd., 2014, 2018). Özet olarak $\chi$ değerinin bulunması için kullanılan eşitlik ikinci denklemde sunulmuştur:

$$
\div=\int_{x b}^{x}\left(\frac{A_{0}}{A(x)}\right)^{m / n} d x
$$

Bu eşitlikte $A_{0}$ akaçlama alanını tanımlar. Dönüştürülmüş koordinat olan $\chi$ uzunluk ve yükseklik boyutuna sahiptir. $\chi$ değeri temel olarak, baştan bilinmeyen (a priori) ancak referans konkavlık değerine dayanan $m / n$ oranına göre belirlenir. $\mathrm{m} / \mathrm{n}$ oranının belirlenmesi için dört yöntem kullanılır: (a) akaçlama alanları içerisinde kalan tüm akarsu yerlerinin $\chi$ profilleri üzerinde eş doğrusallık analizi, (b) Monte-Carlo yöntemi ve iterasyonla belirlenen $\chi$ profilleri üzerinde eş doğrusallık analizi, (c) akaçlama alanı içerisinde kalan tüm akarsu yerlerinin eğim-alan ilişkisi ve (d) akaçlama alanı içerisinde kalan akarsu parçalarının eğim-alan ilişkisi. Bu aşamalardan sonra belirlenen $\chi$ değerlerinin, $\chi$ uzayındaki değişimi $(\mathrm{M} \chi)$ ile karşılaştırılması çalışma bölgesinde topoğrafyanın düşey değişim tarihçesi (ör: tektonik yükselme) hakkında bilgi verir (Mudd vd., 2014, 2018).

MF boyunca belirlenen akaçlama havzalarının $\chi$ analizi için LSDTopoTools aracı (Mudd vd., 2018) kullanılarak yukarıda bahsedilen $m / n$ oranları hesaplanmış ve sonrasında $\chi$ değerleri ve $\chi$-M $\chi$ uzayındaki değişim grafikleri üretilmiştir. Bu grafiklerde, profillerin $\chi(\mathrm{m})$ ekseni boyunca düşük veya yüksek değerlere çıkması, söz konusu düşey topoğrafya değişim süresinin kısa veya uzun olmasına işaret eder. $\chi$ uzayında değişim ekseni $(\mathrm{M} \chi)$ ise akaçlama alanı için en eskiden günümüze göreceli zaman basamaklarına karşılık gelir. Özetle elde edilen $\chi$ (chi) grafiklerinde düşey eksende ifade edilen göreceli eksen zaman aralıkları, yatay eksende ise düşey topoğrafya değişiminin ne kadar sürdüğünü görsel olarak ifade gösterir.

\section{Morfometrik Analizlerden Elde Edilen Bulgular \\ 4.1. Hipsometrik Analizler}

MF boyunca belirlenen bütün akaçlama havzaları için hipsometrik analizler gerçekleştirilmiştir (Şekil 2b). Elde edilen sonuçlar fayın geometrik segmentasyonuna göre sınıflandırılmış, analiz sonuçlarının tamamı her bir akaçlama havzası için Çizelge 1'de özetlenmiştir.

Bu sonuçlara göre, MF'nin kuzey kesimlerini oluşturan FS1 geometrik segmentini kesen akaçlama havzaları $(\mathrm{H} 1,2,3,4,5$ ve 6) 0.5021 ile 0.6777 arasında değişen yüksek HI değerlerine sahiptir (Şekil $2 b$ ve Çizelge 1). Fayın doğrultusu boyunca güneye doğru devam edildiğinde, HI'lerin göreceli olarak düştügü gözlenir. FS2 boyunca, 0.332 ila 0.4481 aralığında sonuçlar elde edilmişken, istisna olarak $\mathrm{H} 10$ için 0.2514 bulunmuştur. FS3 ve yakın civarında HI değerleri değişken bir dağılıma sahiptir. Bu segmentin kuzey kesimlerinde havzalar 0.3 ila 0.5 HI'lere sahipken, belirgin bir jog görülen orta kesiminde 0.25 civarına düşme, güney tarafina doğru ise yeniden değerlerde yükselme görülür. Birbirlerine paralel iki kısa fay parçasından oluşan FS4 ve FS5 civarında akaçlama havzaları 0.37 ila 0.4061 arasında değişen $\mathrm{HI}$ değerlerine sahiptir.

\subsection{Diklik Ve Konkavlık Analizleri $\left(k_{s n}, \theta\right)$}

Hesaplanan normalize diklik değerleri, büyüklüklerine göre dört grupta sınıflandırılmıştır (Şekil 2b). Yüksek diklik değerleri (>100) genelde FS1 segmenti boyunca gözlenir. Yüksek ve orta (50-100) değerlere sahip akarsular, genelde FS2, FS3'ün güney kesimleri ve FS4 civarındadır. Düşük $(<50)$ değerler ise özellikle FS3'ün kuzey kesimlerinde dikkati çeker. H2 ve H3 no'lu akaçlama havzaları en büyük diklik değerlerinin (>250) hesaplandığı yerlerdir. $\mathrm{H} 7$ ve $\mathrm{H}^{\prime}$ 'de ise, havzanın genelinde akarsular orta-düşük dikliğe sahipken, faya yakın kesimlerde büyük ihtimalle tektonizmanın etkisi ile değerlerin yükseldiği görülür. Fayın üzerinde yer aldığı halde, en düşük dikliğe sahip havza H10'dur.

Tablo 1. MF boyunca belirlenen akaçlama havzaları, bunların alanları ve hesaplanan $\mathrm{HI}$ ve Konkavlık değerleri.

Table 1. Hypsometric integrals (HI) and concavity values of drainage basins along the Malatya Fault.

\begin{tabular}{|l|r|r|r|}
\hline Havza & Alan (km2) & \multicolumn{1}{l|}{ H } & Konkavlık \\
\hline H1 & 31.08 & 0.5021 & 0.1645 \\
\hline H2 & 86.04 & 0.6295 & 0.4487 \\
\hline H3 & 24.46 & 0.6777 & 0.2152 \\
\hline H4 & 28.72 & 0.6188 & 0.2107 \\
\hline H5 & 18.3 & 0.6067 & 0.3872 \\
\hline H6 & 34.93 & 0.5025 & 0.4621 \\
\hline H7 & 90.85 & 0.4481 & 0.2575 \\
\hline H8 & 102.1 & 0.4465 & 0.3388 \\
\hline H9 & 102.8 & 0.332 & 0.4432 \\
\hline H10 & 96.28 & 0.2514 & 0.4686 \\
\hline H11 & 28.69 & 0.4223 & 0.3688 \\
\hline H12 & 45.9 & 0.4003 & 0.2298 \\
\hline H13 & 20.46 & 0.442 & 0.2677 \\
\hline H14 & 23.38 & 0.4761 & 0.2434 \\
\hline H15 & 186.3 & 0.3749 & 0.3372 \\
\hline H16 & 93.3 & 0.3419 & 0.3279 \\
\hline H17 & 60.21 & 0.2531 & 0.2574 \\
\hline H18 & 143.5 & 0.271 & 0.3812 \\
\hline H19 & 13.08 & 0.2569 & 0.5281 \\
\hline H20 & 38.69 & 0.3124 & 0.4189 \\
\hline H21 & 71.85 & 0.2371 & 0.2555 \\
\hline H22 & 56.1 & 0.3957 & 0.2756 \\
\hline H23 & 47.69 & 0.3515 & 0.3435 \\
\hline H24 & 0.3515 & 0.156 \\
\hline H25 & 0.2749 & 0.0267 \\
\hline H26 & 0.3478 & 0.2092 \\
\hline H27 & 0.4061 & 0.3372 \\
\hline
\end{tabular}


Konkavlık ise genelde 0.3 ila 0.45 arasında değerler alır. En yüksek konkavlık değeri 0.5281 ile $\mathrm{H} 19$ 'da görülürken, en düşük oran 0.0267 ile H25 için hesaplanmıştır. Konkavlık değerlerinin fay segmentlerine göre dağılımı incelendiği zaman, 0.3-0.45 arasındaki değerlerin genelde FS2 boyunca sıralandığını, diğer segmentlerde ise geniş bir değer saçılımının olduğu görülür (Çizelge 1).

\subsection{Boyuna Profillerin İntegral Analizi $(\chi)$}

MF ve civarında özellikle fayın geometrisi ve saha gözlemlerine bağı ılarak yükselme beklenen akaçlama havzaları seçilerek, boyuna profil integral analizleri gerçekleştirilmiştir. Seçilen havzalar; FS2 boyunca $\mathrm{H} 7$ ve onun iki komşusu $\mathrm{H} 6$ ve $\mathrm{H} 8$, FS3 boyunca ise $\mathrm{H} 15, \mathrm{H} 16$ ve $\mathrm{H} 18^{\prime}$ dir.

FS2 segmenti üzerinde yer alan H6 havzası için gerçekleştirilen integral analizinde $\mathrm{m} / \mathrm{n}$ parametresi, hesaplamaya katilan akarsu kollarının sayısının değişkenliği (farklı Strahler derecesinde akarsu kabulü) yüzünden 0.29 ila 0.375 arasında değişir. $\mathrm{Bu}$ havzanın komşuları olan $\mathrm{H} 7$ ve $\mathrm{H} 8$ için ise bu parametre sırasıyla 0.29-0.575 ila 0.525-0.53 arasındadır. Her bir akaç-
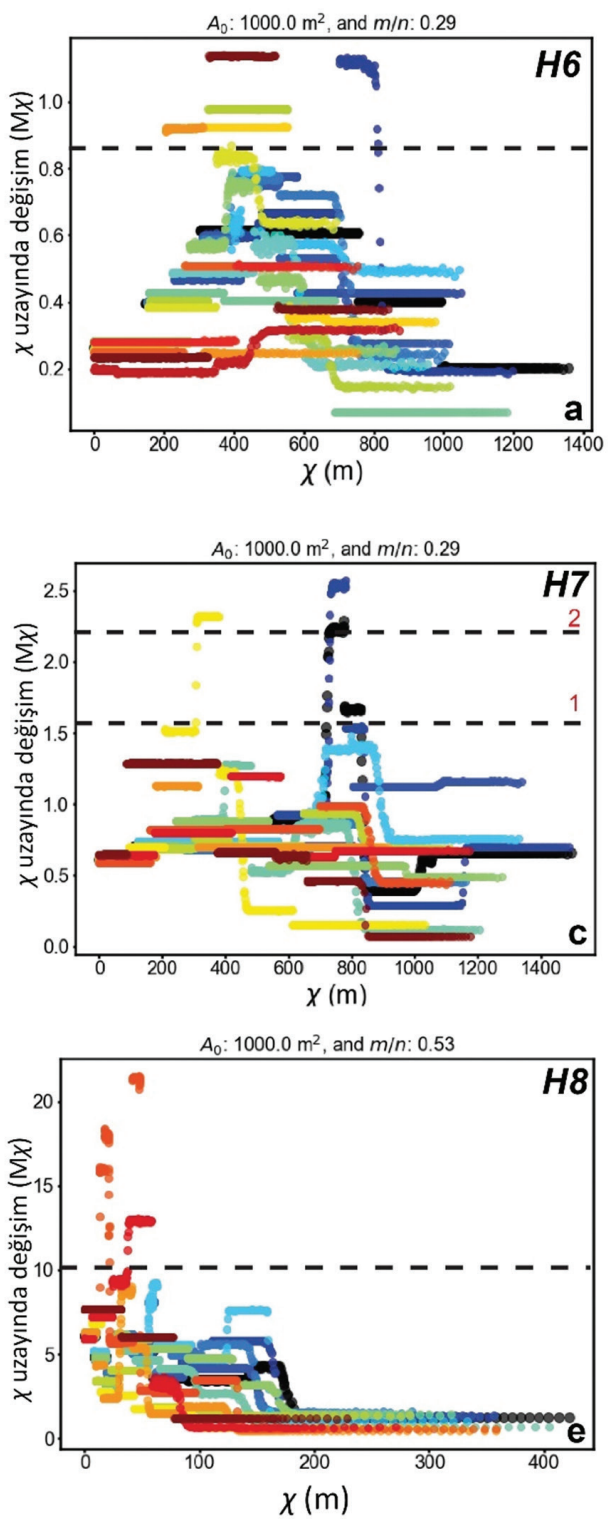

lama alanı için $\mathrm{m} / \mathrm{n}$ sınır değerlerine göre chi-chi uzayındaki değişim $(\chi-\mathrm{M} \chi)$ grafikleri hazırlanmıştır. $\mathrm{H} 6$ için hazırlanan grafiklere göre, $\chi$ eksenindeki değerlerin, farklı $M \chi$ değerlerinde neredeyse eşit olması, akaçlama havzası içindeki bütün akarsu kollarının deformasyona eşit tepki verdiklerini ve bu sürecin her akaçlama üyesinde yüksek $\chi$ alacak kadar uzun sürdüğünü gösterir. $\mathrm{M} \chi$ ekseni boyunca, orijinden siyah kesikli çizgiye kadar kesintisiz profillerin devam etmesi, topoğrafyadaki düşey değişiminin kesintisiz devam ettiğine işaret eder (Şekil 3a ve b). $\mathrm{H} 7$ havzası için elde edilen $\chi-\mathrm{M} \chi$ grafikleri, sahip oldukları yüksek $\chi$ ile kaynak bölgesinde dikleşmeye karşılık gelir. $\mathrm{M} \chi$ ekseninde orijin ile 1 no'lu kesikli siyah çizgiye kadar profillerin devam etmesi, topoğrafyadaki düşey değişimin sürekliliğini temsil eder. 1 ve 2 no'lu kesikli çizgiler arasında yatay profillerin oluşmaması, düşey topoğrafya değişiminin yani yükselmenin bir süre durduğunu ifade eder (Şekil $3 c$ ve d). $\mathrm{H} 8^{\prime}$ in aynı analiz sonuçlarına göre, kaynak alanındaki dikleşme uzun süreli bir yükselmeye karşılık gelir. Bu havza için üretilen grafiklerde, siyah kesikli çizgi sonrası profillerde gözlenen devamsızlıklar, havza içindeki her dere kolunun yükselmeden eş etkilenmediğini işaret eder (Şekil 3e ve f).
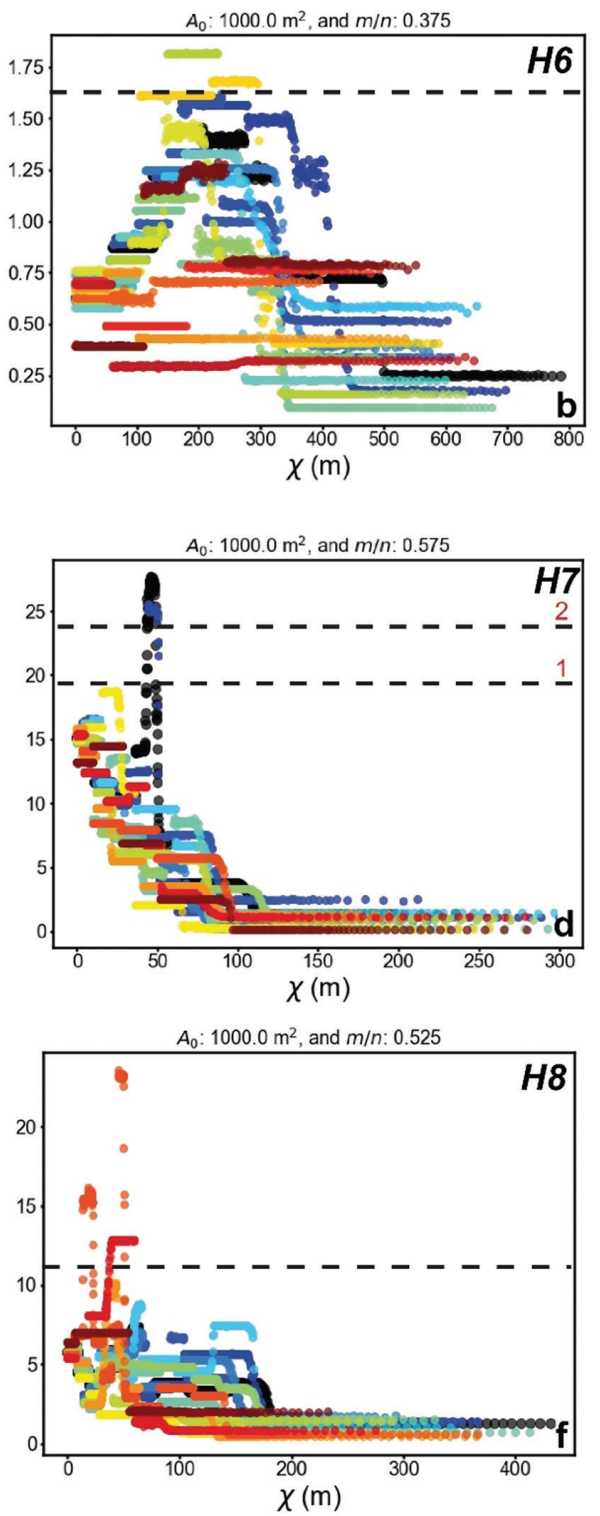

Şekil 3. (a) ve (b) H6, (c) ve (d) H7, (e) ve (f) H8 akaçlama havzalarının farklı sayıda kolları hesaba katılarak üretilmiş $\chi$ - $\mathrm{M} \chi$ grafikleri.

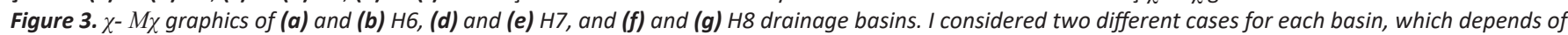
on the number of streams in integral calculations. 

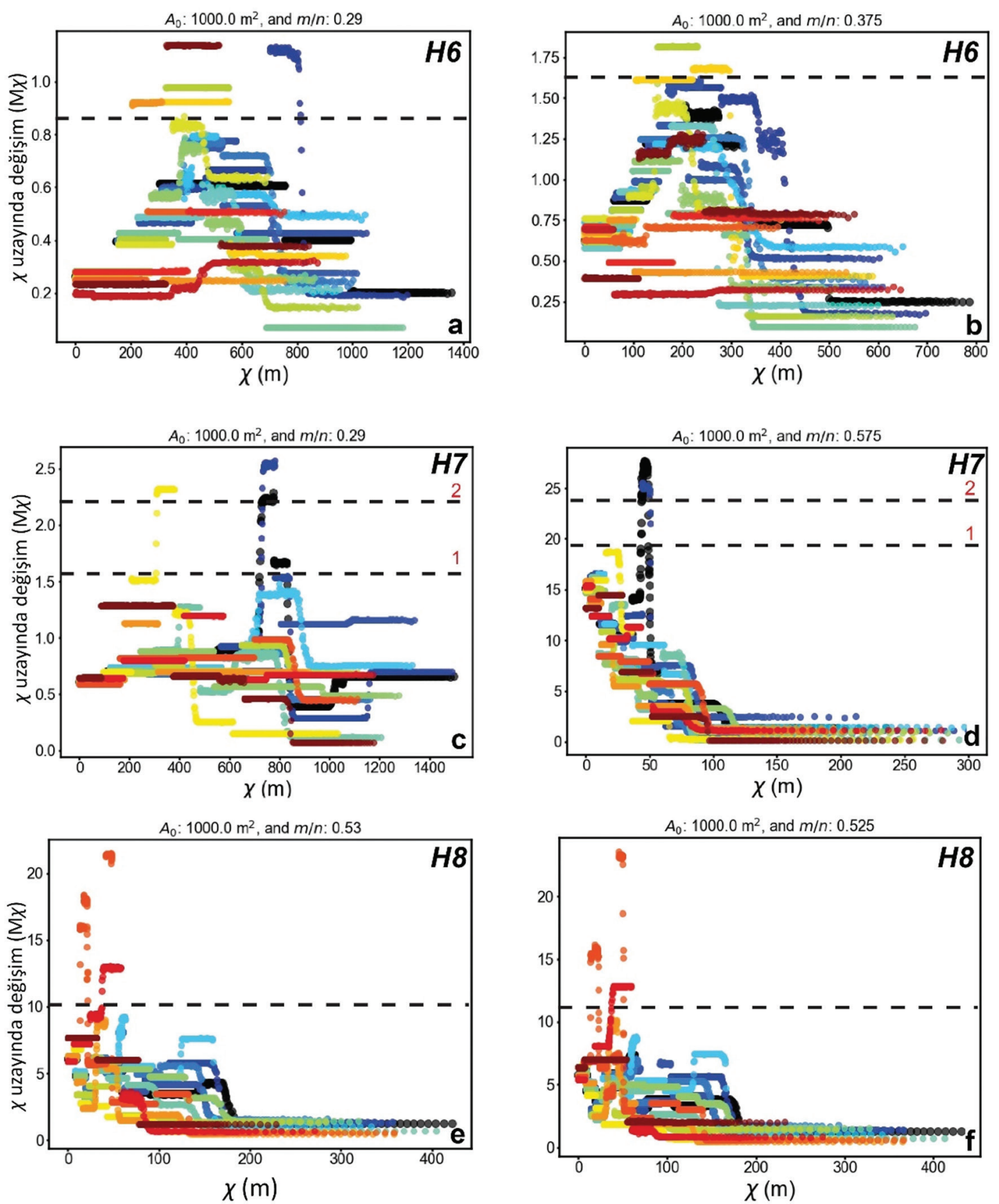

Şekil 4. (a) ve (b) H15, (c) ve (d) H16, (e) ve (f) H18 akaçlama havzalarına farklı sayıda kolları hesaba katılarak üretilmiş $\chi$ - M $\chi$ grafikleri.

Figure 4. $\chi-M \chi$ graphics of (a) and (b) H15, (d) and (e) H16, and (f) and (g) H18 drainage basins. I considered two different cases for each basin, which depends of on the number of streams in integral calculations.

MF boyunca integral analizinin uygulandığı diğer bir segment olan FS3'te iki farklı bölge incelenmiştir. Birinci bölgede birbirine komşu $\mathrm{H} 15$ ve 16 ve ikinci bölgede $\mathrm{H} 18$ akaçlama havzaları çalışılmıştır. $\mathrm{H} 15$ ve $\mathrm{H} 16$ için ne kadar akarsu kolunun hesaba katıldığına bağlı olarak sırasıyla $0.43-0.45$ ve $0.35-0.525 \mathrm{~m} / \mathrm{n}$ değerleri bulunmuştur. Bu oranlar kullanılarak üretilen $\chi-\mathrm{M} \chi$ grafiklerine göre, $\mathrm{H} 15$ 'de kaynak alanda dikleşme dikkati çeker. Bu havzada ayrıca 1 no'lu kesikli çizgiye kadar kesintisiz bir yükselim olduğu görülür. 1 ve 2 no'lu kesikli çizgiler arasında yatay profil olmaması, topoğrafyada düşey değişimlerin düşmesine karşılık gelir. Aynı grafiklere göre 2 no'lu çizginin üzerinde yükselim yeniden başlamıştır (Şekil 4a ve b). H16'da da durum hemen hemen aynıdır (Şekil $4 c$ ve d). Biraz daha güneyde yer alan ve 0.47-0.6 arasında değişen $\mathrm{m} / \mathrm{n}$ oranlarına sahip
H18 havzası için oluşturulan chi-grafiği, birinci kesikli çizgiye kadar sürekli devam eden yükselim süresinde dere kollarının tamamının bu düşey değişime tepki verdiğini gösterir. Bu grafiğe göre, 1 no'lu kesikli çizgiye kadar neredeyse bütün dere kolları uzun bir süre, kesintisiz yükselime maruz kalmıştır. 1 ve 2 no'lu kesikli çizgiler arasında yatay profil olmaması yükselimin durduğunu ve yeni bir taraça seviyesinin oluşabileceğine işaret eder. 2 ve 3 no'lu kesikli çizgiler arasında gerçekleşen deformasyon sonucu taraçalar yükselmiş olmalıdır. Şekil 4e'de görülen 3 ve 4 arasındaki düşey topoğrafya değişiminin durması, en genç taraça seviyesi oluşumuna karşılık gelir. 4 no'lu kesikli çizginin üzerinde gözlenen yatay profiller, en genç yükselim evresini yansıtır. 


\section{Tartş̧ma ve Sonuçlar}

MF'nin beş geometrik segmenti boyunca toplam 27 adet akaçlama havzası belirlenmiş ve farklı araçlar kullanılarak bu havzalar üzerinde sırasıyla hipsometrik $(\mathrm{HI})$, konkavlık $(\theta)$ - normalize diklik $\left(k_{s n}\right)$ ve boyuna profillerin integral $(\chi)$ analizleri gerçekleştirilmiştir.

Morfolojinin olgunluk derecesini temsil eden HI, MF'nin en çok FS1 kesiminde yer alan havzalar için yüksek değerler vermiştir (Şekil $2 b$ ve Çizelge 1). Bu havzaların akaçlama ağlarının sahip olduğu yüksek normalize diklik $\left(k_{s n}\right)$ değerleri, özellikle bu bölgenin MF boyunca en büyük yükselim gösteren kısmı olduğunu destekler. Bölgede ayrıca $V$ biçimli ve derin vadi oluşumları dikkati çeker (Şekil 5b). FS1 boyunca bu yüksek morfometri değerlerinin ölçüldüğü akaçlama havzaları (H1-H6), temel olarak Mesozoyik kireçtaşı, Kretase ofiyolitik melanjı, Eosen-Miyosen marn-kireçtaşı ardalanması ve Tersiyer volkanikleri olmak üzere toplam dört farklı litolojik birim üzerinde yer alır. Bunlar arasında tek bir litolojik birim içinde yer alan havza ile birden fazla litolojiyi kesen havzanın HI değerleri arasında bir fark yoktur $(\mathrm{HI}>0.5)$. Diğer bir yandan $\mathrm{H} 2$ havzasında Kretase melanjı ve Mesozoyik kireçtaşları arasında sahip oldukları sınır boyunca yüksek $k_{s n}$ değerleri dikkati çekerken, komşu H3 havzasının tamamı Mesozoyik kireçtaşı içinde kalmasına rağmen benzer $k_{s n}$ değerleri (>100) görülür. MOFZ içerisinde, yaklaşık $\mathrm{K} 65^{\circ}-70^{\circ} \mathrm{D}$ doğrultusuna sahip OF'nin, bu bölgede saat yönünde bükülmesi ve güneye doğu kabaca K-G doğrultusunda MF olarak devam etmesi, iki fay parçası arasında kalan kama şekilli gövdenin düşey deformasyona uğraması için en büyük sebeptir. OF'nin kuzeyinde ve MF'nin doğusunda kalan bu alan, tektonik etkinlik içerisinde blok hareketleri ve blok sınırlarına bağlı olarak yükselmektedir. Bu yükselme ve ona eşlik eden toplam hacim sıkışması bölgede yapılan yapısal jeoloji (Kaymakçı vd., 2006) ve tektonik jeomorfoloji (Yazıcı vd., 2018a) çalışmalarıyla açık bir şekilde ortaya konmuştur. Özetle, FS1 boyunca belirlenen akaçlama havzalarında görülen ve düşey topoğrafya değişimi olarak yorumlanan morfometri değerleri, litolojiden bağımsız olarak tektonizma kökenli yükselmeyi gösterir.

Düşey deformasyon şiddetinde ikinci sırada, FS2 ile FS3 segmentinin kuzey kesimleri bulunur. FS2 boyunca belirlenen akaçlama havzalarının tamamı (H7-H11) ve FS3'ün kuzey kesimlerini temsil eden $\mathrm{H} 12-\mathrm{H} 14$ havzaları Tersiyer volkaniklerinin üzerinde yer alır. Bu alanlarda HI 0.3 ile 0.5 arasında değerler alırken, $k_{S n}$ 50-100 veya $100-250$ aralığındadır (Şekil $2 b$ ). Tek istisna düşük $\mathrm{HI}$ ve $k_{s n}$ değerlerine sahip olan $\mathrm{H} 10$ havzasıdır. MF'nin kuzey kesimlerinde volkanik birimleri kesen havzalarda ölçülen $\mathrm{HI}$ ve $k_{S n}$ değerlerinin, FS2'nin tamamı ve FS3'ün kuzey havzalarında benzer litolojilerin üzerinde görülen havza değerlerinden yüksek kalması, bu kesimler için yeryüzünü şekillendiren faktörlerden litolojiden çok tektonik kuvvetlerin etken olduğuna işaret eden diğer bir göstergedir. H10 havzasında görülen düşük değerlerin ana sebebi ise FS2 ila FS3'ün tam bu bölgede açılmalı sıçrama yaparak, bölgede yükselmenin etkisini dengeleyecek bir gerilmeye yol açmasıdır. FS3'ün güney kesimleri $(\mathrm{H} 15-\mathrm{H} 24)$ ile birbirine paralel uzanan FS4 ve FS5 boyunca ( $\mathrm{H} 25-\mathrm{H} 27)$ belirlenen akaçlama havzaları ise çok daha geniş bir litolojik çeşitlilik üzerinde yer alır. FS3'ün güney kesimlerinde fay genelde Eosen-Oligosen yaşlı kırıntılı istifler ve karbonatı kayaçlar ile genç (Pliyo-Kuvaterner) kırıntılı çökel birimler arasında sınırı oluşturur. Saha gözlemleri sırasında da gözlenen basamaklı taraça sistemleri, az veya zayıf tutturulmuş bu genç çökeller içerisinde yer alır (Şekil $5 d$ ). Bu zayıf dayanıma sahip litolojik birimlerin daha kolay aşınacağı ne kadar doğru olsa da, bu bölgede fay blokları arasında meydana gelen göreceli düşey hareket ve genç çökelmenin de bunun kontrolünde gerçekleşmesi (Kaymakçı vd., 2006) kesinlikle göz önünde bulundurulmalıdır. HI ve $k_{S n}$ değerlerine göre en düşük topoğrafik değişime maruz kalan havzalar $\mathrm{H} 17$ ve $\mathrm{H} 25^{\prime}$ tir (Şekil $2 b$ ve Çizelge 1).

Saha çalışmaları sırasında taraça oluşumu gözlenen havzalar (Şekil 5) ve yüksek $\mathrm{HI}$ ve $k_{s n}$ değerlerine sahip akaçlama unsurları üzerinde ek olarak boyuna profillerin integral analizi $(X)$ uygulanmıştır (Şekil 3 ve 4). Analiz edilen havzalardan H7, FS1 ve FS2 segmentlerinin sınırında yer alırken, H6 FS1, H8 ise FS2 üzerindedir. Her üç havzanın da maruz kaldığı düşey topoğrafik değişim ve dere kollarının buna tepkisinin tarihçesi ortaya çıkartılmış, özellikle taraça oluşum aşamaları morfometrik olarak gösterilmiştir. İntegral analizi ile elde edilen bu bulguyu, H7'inin ana kolunu oluşturan Kantarmış Deresi'nde gözlenen taraçalar destekler (Şekil 5a). İki taraça seviyesinden yaşlı ola$\mathrm{nı}$ güncel dere seviyesinden $18 \mathrm{~m}$ daha yukarıdadır ve Şekil $3 c$ ve d'de 1 numaralı kesikli çizgiye kadar olan yükselim sürecinden önce oluşmuş ve bu süreçle günümüzdeki konumunu kazanmıştır. FS3 üzerinde gerçekleştirilen $\chi$ analizleri ile $\mathrm{H} 15$, 16 ve 18 no'lu havzalar incelenmiştir. Ana gövdesini Kuruçay'ın oluşturduğu H15, iki kesikli siyah çizgi yani yükselim ve düşey topoğrafik değişimin durduğu zaman aralıkları ile karakterize olurken, bu akaçlama unsurunun üzerinde yine iki adet taraça seviyesi tespit edilmiştir (Şekil 5c). Bunlardan yaşlı olan günümüzdeki seviyesine Şekil $4 a$ ve b'de gösterilen 1 ve 2 no'lu kesikli çizgiler arasında ve 2 no'lu kesikli çizgiden sonra dikkati çeken düşey topoğrafik değişim süreçlerinde yükselmiştir. Günümüzde daha genç olan ve Kuruçay'ın güncel seviyesine daha yakın görülen taraça seviyesi ise 1 ve 2 no'lu kesikli çizgilerin arasında kalan zaman sürecinde oluşmuş, 2 no'lu kesikli çizginin üzerinde görülen yükselimden etkilenmiştir. Saha gözlemleri sırasında çok basamaklı taraça morfolojisinin görüldüğü diğer bir bölge ise Tohma Çayı ve H18 akaçlama havzasıdır (Şekil 5d). Bu bölge için uygulanan $\chi$ analizi, birbirini takip eden iki farklı yükselim ve bunların arasında kalan durgunluk süreçlerini gösterir (Şekil 4e ve f). Buna göre Tohma'nın en eski taraçası iki süreç etkisi ile birden yükselirken, yükselimin ikinci kez durduğu zaman aralığında en genç taraça seviyesi oluşmuştur.

Morfometrik analizler, özellikle saha tabanlı jeomorfoloji ve jeoloji bilgisinin az olduğu bölgeler için çok önemli bilgiler sunar. Ancak göreceli olarak yeni olan bu yöntemlerin tek katkısı bunla sınırlı olmayıp, saha gözlemleri/ölçümleri ve Kuvaterner çökellerinin yaşlandırılmasında kullanılan radyometrik yöntemler ile desteklendikleri zaman bir bölgenin yeryüzü şekillerinin evrimi üzerine bütüncül bir bakış açısı sağlar. MF özelinde uygulanan morfometrik indisler, fayın farklı kesimleri için düşey topoğrafya değişimi hakkında bilgi vermekle kalmamış, aynı zamanda birbirini takip eden yükselme ve duraksama süreçlerine ve yer şekillerinin daha iyi anlaşılması için yeni çalışma noktalarına işaret etmiştir. 

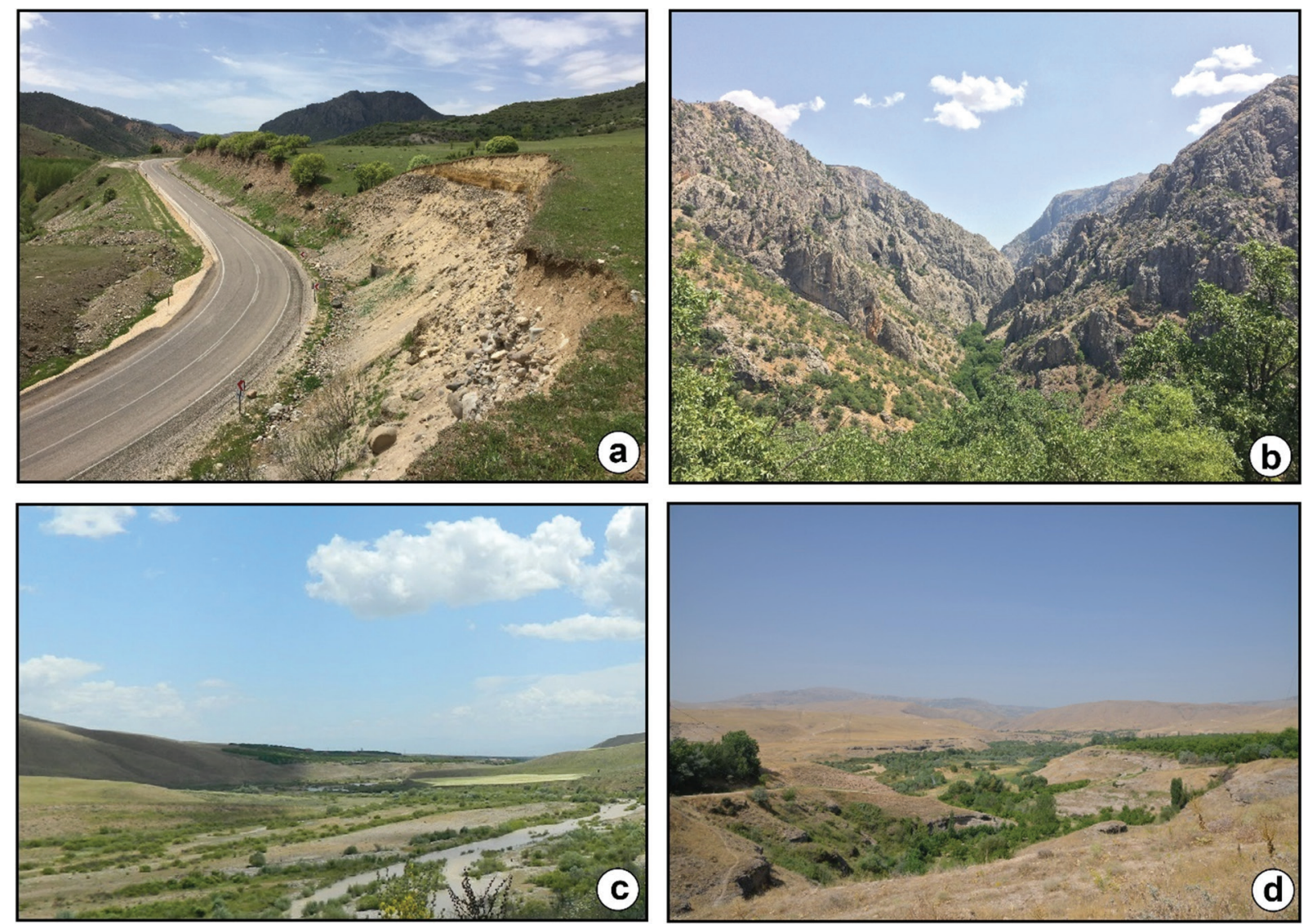

Şekil 5. (a) H7 içinde Kantarmış deresinde gözlenen taraça seviyeleri, (b) H4, 5 ve 6 no'lu havzaların bulunduğu alanda bu akaçlamaların bağlandığı ana akarsu kolunun sahip olduğu derin ve V şekilli vadi, (c) Geniş yayvan bir vadiye sahip olan Kuru Dere (H15) ve taraçaları, (d) Tohma Çayı (H18) ve basamaklı taraça seviyeleri.

Figure 5. (a) The upper terrace of the Kantarmış Dere in the H7 drainage basin. (b) The deeply incised V-shaped valley, which connects the H4, 5 and 6 basins. (c) Kuru Dere terraces in the U-shaped valley within the H15 basin. (d) The staircase terraces of the Tohma River within the H18 basin.

\section{Katkı Belirtme}

Bu çalışma TÜBITAK 114 Y580 no'lu proje kapsamında gerçekleştirilmiştir. Yazar, yayının düzeltilmesi konusunda tenkitleri ve ilgileri için sayın editör Cihan Bayrakdar ve hakemlere teşekkürü bir borç bilir.

\section{Kaynakça}

Acarel, D., Cambaz, M. D., Turhan, F., Mutlu, A. K. ve Polat, R. (2019). Seismotectonics of Malatya Fault, Eastern Turkey. Open Geosci. 11(1): 1098-1111.

Aktuğ, B., Parmaksız, E., Kurt, M., Lenk, O., Kılıçoğlu, A., Gürdal, M. A. ve Özdemir, S. (2013). Deformation of Central Anatolia: GPS implications. Journal of Geodynamics 67: 78-96.

Akyüz, H. S., Uçarkuş, G., Altunel, E., Doğan, B. ve Dikbaş, A. (2012). Paleoseismological investigations on a slow-moving active fault in Central Anatolia, Tecer Fault, Sivas. Ann. Geophys. 55: 847-857.

Armijo, R., Meyer, B., Hubert-Ferrari, A. ve Barka, A. A. (1999). Westward propagation of North Anatolian Fault into the Northern Agean: timing and kinematcis. Geology 27: 267-270.

Bilgiç, T. (2002). 1:500000 Ölçekli Türkiye Jeoloji Haritası, Sivas Paftası. Maden Tetkik ve Arama Genel Müdürlügü. Ankara.

Bozkurt, E. (2001). Neotectonics of Turkey; a synthesis. Geodinamica Acta 14: 3-30.

Bubenzer, O. Ve Bolten, A. (2008). The use of new elevation data (SRTM/ASTER) for the detection and morphometric quantification of Pleistocene megadunes (draa) in the eastern Sahara and the southern Namib. Geomorphology 102(2): 221-231.

Burbank, D.W. ve Anderson, R.S. (2011). Tectonic Geomorphology. West Sussex: John Wiley \& Sons. xiv+454 s.
Castillo, M., Muñoz-Salinas, E. ve Ferrari, L. (2014). Response of a landscape to tectonics using channel steepness indices $(\mathrm{ksn})$ and OSL: A case of study from the Jalisco Block, Western Mexico. Geomorphology 221: 204-214.

Chen, Y. C., Sung, Q. Ve Cheng, K. Y. (2003). Along-strike variations of morphotectonic features in the Western Foothills of Taiwan: tectonic implications based on stream-gradient and hypsometric analysis. Geomorphology 56: 109-137.

Chorowicz, J., Dhont, D. ve Gündogdu, N. (1999). Neotectonics in the eastern North Anatolian fault region (Turkey) advocates crustal extension: mapping from SAR ERS imagery and Digital Elevation Model. J. Struct. Geol. 21: 511-532.

Clark, M. K., Schoenbohm, L. M., Royden, L. H., Whipple, K. X., Burchfiel, B. C., Zhang, X., Tang, W., Wang, E., Chen, L. (2004). Surface uplift, tectonics, and erosion of eastern Tibet from large-scale drainage patterns. Tectonics 23: TC1006.

Çılğın, Z. ve Bayrakdar, C. (2020). Teke Yarımadası'ndaki (Güneybatı Anadolu) glasiyal sirklerin morfometrik özellikleri. Türk Coğrafya Dergisi 74: 107-121.

Denizman, C. (2003). Morphometric and spatial distribution parameters of karstic depressions, Lower Suwannee River Basin, Florida. Journal of Cave and Karst Studies 65(1): 29-35.

Emre, Ö., Duman, T.Y., Özalp, S., Elmacı, H., Olgun, Ş. ve Şaroğlu, F. (2013). Açıklamalı Türkiye Diri Fay Haritası Ölçek 1:1250000 (Active Fault Map of Turkey with an Explanatory Text 1:1250000 scale). Maden Tetkik ve Arama Genel Müdürlüğü, Ankara.

Faccenna, C., Becker, T. W., Jolivet, L. ve Keskin, M. (2013). Mantle convection in the Middle East: Reconciling Afar upwelling, Arabia indentation and Aegean trench rollback. Earth Planet. Sci. Lett. 375: 254-269.

Flint, J. J. (1974). Stream gradient as a function of order, magnitude, and discharge. Water Resour. Res. 10: 969-973. 
García-Ruiz, J. M., Gómez-Villar, A., Ortigosa, L. ve Martí-Bono, C. (2000). Morphometry of glacial cirques in the central Spanish Pyreenes. Geografiska Annaler: Series A. Physical Geography. 82(4): 433-442.

Hack, J. T. (1957). Studies of Longitudinal Stream Profiles in Virginia and Maryland. vol. 294. US Government Printing Office.

Hack, J. T. (1973). Stream-profile analysis and stream-gradient index. J. Res. US Geol. Surv. 1: 421-429.

Higgins, M., Schoenbohm, L. M., Brocard, G., Kaymakçı, N., Gosse, J. C. ve Cosca, M. A. (2015). New kinematic and geochronologic evidence for the Quaternary evolution of the Central Anatolian fault zone (CAFZ). Tectonics 34: 2118-2141.

Kaymakçı, N., İnceöz, M. ve Ertepınar, P. (2006). 3-D Architecture and Neogene Evolution of the Malatya Basin: Inferences for the Kinematics of the Malatya and Ovacık Fault Zone. Turkish J. Earth Sci. 15: 123-154.

Keller, E. A. ve Pinter, N. (1996). Active Tectonics. New Jersey: Prentice Hall.

King, C. A. M. (1982). Morphometry in glacial geomorphology in: Coates, D. R. (ed) Glacial Geomorphology. Dodrect: Springer 147-162.

Kirby, E. ve Whipple, K. (2001). Quantifying differential rock-uplift rates via stream profile analysis. Geology 29(5): 415-418.

Kirby, E., Whipple, K. X., Tang, W. ve Chen, Z. (2003). Distribution of active rock uplift along the eastern margin of the Tibetan Plateau: inferences from bedrock channel longitudinal profiles. J. Geophys. Res. Solid Earth 108(B4): 2217.

Kirby, E., Johnson, C., Furlong, K. ve Heimsath, A. (2007). Transient channel incision along Bolinas Ridge, California: evidence for differential rock uplift adjacent to the San Andreas fault. J. Geophys. Res. Earth Surf. 112: F03S07.

Koçyiğit, A. ve Beyhan, A. (1998). A new intracontinental transcurrent structure: the Central Anatolian Fault Zone, Turkey. Tectonophysics 284: 317-336.

Le Pichon, X. ve Kreemer, C. (2010). The Miocene-to-Present Kinematic Evolution of the Eastern Mediterranean and Middle East and Its Implications for Dynamics. Annu. Rev. Earth Planet. Sci. 38: 323-351.

McKenzie, D. (1972). Active Tectonics of the Mediterranean Region. Geophys. J. R. Astron. Soc. 30: 109-185.

Miller, S. R., Baldwin, S. L. ve Fitzgerald, P. G. (2012). Transient fluvial incision and active surface uplift in the Woodlark Rift of eastern Papua New Guinea. Lithosphere 4: 131-149.

Molin, P., Pazzaglia, F.J. ve Dramis, F. (2004). Geomorphic expression of active tectonics in a rapidly-deforming forearc, Sila massif, $\mathrm{Ca}$ labria, southern Italy. Am. J. Sci. 304: 559-589.

Mudd, S. M., Attal, M., Milodowski, D. T., Grieve, S. W. D. ve Valters, D. A. (2014). A statistical framework to quantify spatial variation in channel gradients using the integral method of channel profile analysis. J. Geophys. Res. Earth Surf. 119: 138-152.

Mudd, S. M., Clubb, F. J., Gailleton, B. ve Hurst, M. D. (2018). How concave are river channels? Earth Surf. Dyn. 6: 505-523.

Ouimet, W. B., Whipple, K. X. ve Granger, D. E. (2009). Beyond threshold hillslopes: channel adjustment to base-level fall in tectonically active mountain ranges. Geology 37(7): 579-582.

Özener, H., Arpat, E., Ergintav, S., Doğru, A., Çakmak, R., Turgut, B. ve Doğan, U. (2010). Kinematics of the eastern part of the North Anatolian Fault Zone. J. Geodyn. 49: 141-150.

Özeren, M. S. ve Holt, W. E. (2010). The dynamics of the eastern Mediterranean and eastern Turkey. Geophys. J. Int. 183: 1165-1184.

Öztürk, M. Z. (2018). Karstik kapalı depresyonların (dolinlerin) morfometrik analizleri. Coğrafya Dergisi 35: 17-27

Pandey, P. Manickam, S., Bhattacharya A., Ramanathan, A. L., Singh, G. ve Venkataraman, G. (2017). Qualitative and quantitative assessment of TanDEM-X DEM over western Himalayan glaciated terrain. Geocarto International 32(4): 442-454.

Paul, A., Karabulut, H., Mutlu, A.K. ve Salaün, G. (2014). A comprehensive and densely sampled map of shear-wave azimuthal anisotropy in the Aegean-Anatolia region. Earth Planet. Sci. Lett. 389: 14-22.
Pérez-Peña, J. V., Azañón, J. M., Azor, A., Tuccimei, P., Della Seta, M. ve Soligo, M. (2009). Quaternary landscape evolution and erosion rates for an intramontane Neogene basin (Guadix-Baza basin, SE Spain). Geomorphology 106: 206-218.

Pérez-Peña, J. V., Azor, A., Azañón, J. M. ve Keller, E. A. (2010). Active tectonics in the Sierra Nevada (Betic Cordillera, SE Spain): insights from geomorphic indexes and drainage pattern analysis. Geomorphology 119: 74-87.

Perron, J. T. ve Royden, L. (2013). An integral approach to bedrock river profile analysis. Earth Surf. Process. Landforms 38: 570-576.

Philippon, M., Brun, J.-P., Gueydan, F. ve Sokoutis, D. (2014). The interaction between Aegean back-arc extension and Anatolia escape since Middle Miocene. Tectonophysics 631: 176-188.

Reilinger, R., McClusky, S., Vernant, P., Lawrence, S., Ergintav, S., Çakmak, R., Özener, H., Kadirov, F., Guliev, I., Stepanyan, R., Nadariya, M., Hahubia, G., Mahmoud, S., Sakr, K., ArRajehi, A., Paradissis, D., Al-Aydrus, A., Prilepin, M., Guseva, T., Evren, E., Dmitrotsa, A., Filikov, S. V, Gomez, F., Al-Ghazzi, R. ve Karam, G. (2006). GPS constraints on continental deformation in the Africa-Arabia-Eurasia continental collision zone and implications for the dynamics of plate interactions. J. Geophys. Res. Solid Earth 111: B05411.

Sağlam Selçuk, A. (2016). Evaluation of the relative tectonic activity in the eastern Lake Van basin, East Turkey. Geomorphology 270: 9-21.

Sançar, T. (2018). Yüksekova Havzası'nın (Güneydoğu Türkiye) yükselim hızı tarihçesinin araştrılması. Türkiye Jeoloij Bülteni 61: 207-240.

Sançar, T., Zabcı, C., Karabacak, V., Yazıcı, M. ve Akyüz, H. S. (2019). Geometry and Paleoseismology of the Malatya Fault (Malatya-Ovacık Fault Zone), Eastern Turkey: Implications for intraplate deformation of the Anatolian Scholle. J. Seismol. 23: 319-340.

Sançar, T., Zabcı, C., Akçar, N., Karabacak, V., Yeşilyurt, S., Yazıcı, M., Serdar Akyüz, H., Önal, A.Ö., Ivy-Ochs, S., Christl, M. ve Vockenhuber, C. (2020). Geodynamic importance of the strike-slip faults at the eastern part of the Anatolian Scholle: Inferences from the uplift and slip rate of the Malatya Fault (Malatya-Ovacık Fault Zone, eastern Turkey). J. Asian Earth Sci. 188: 104091.

Sarıkaya, M. A., Yıldııı, C. ve Çiner, A. (2015). No surface breaking on the Ecemiş Fault, central Turkey, since Late Pleistocene ( 64.5 ka); new geomorphic and geochronologic data from cosmogenic dating of offset alluvial fans. Tectonophysics 649: 33-46.

Schoenbohm, L. M., Whipple, K. X., Burchfiel, B. C. ve Chen, L. (2004). Geomorphic constraints on surface uplift, exhumation, and plateau growth in the Red River region, Yunnan Province, China. Geol. Soc. Am. Bull. 116: 895-909.

Schwanghart, W. ve Kuhn, N. J. (2010). TopoToolbox: A set of Matlab functions for topographic analysis. Environ. Model. Softw. 25: 770-781.

Schwanghart, W. ve Scherler, D. (2014). Short Communication: TopoToolbox 2 - MATLAB-based software for topographic analysis and modeling in Earth surface sciences. Earth Surf. Dynam. 2(1): 1-7.

Scotti, V. N., Molin, P., Faccenna, C., Soligo, M. ve Casas-Sainz, A. (2014). The influence of surface and tectonic processes on landscape evolution of the Iberian Chain (Spain): quantitative geomorphological analysis and geochronology. Geomorphology 206: 37-57.

Snyder, N. P., Whipple, K. X., Tucker, G. E. ve Merritts, D. J. (2000). Landscape response to tectonic forcing: digital elevation model analysis of streamprofiles in the Mendocino triple junction region, northern California. Geol. Soc. Am. Bull. 112: 1250-1263.

Sreedevi, P. D., Owais, S., Khan, H. H. ve Ahmed, S., 2009, Morphometric analysis of a watershed of South India using SRTM Data and GIS, Journal Geological Society of India 73: 543-552.

Strahler, A. N. (1952). Hypsometric (Area-Altitude) analysis of erosional topography. Geol. Soc. Am. Bull. 63: 1117-1142.

Şengör, A. M. C. (1980). Türkiye'nin neotektoniğinin esasları (Principles of the Neotectonism of Turkey). Türkiye Jeoloji Kurumu Konferans Serisi, Ankara. 
Şengör, A. M. C., Görür, N. ve Şaroğlu, F. (1985). Strike-slip faulting and related basin formation in zones of tectonic escape: Turkey as a case study, in: Biddle, K.T., Christie-Blick, N. (eds.), Strike-Slip Deformation, Basin Formation, and Sedimentation, Oklahoma: Soc. Econ. Paleontol. Spec. Publ. Society of Economic Paleontologists and Mineralogists. 227-264.

Şengör, A. M. C. ve Zabcı, C. (2019). The North Anatolian Fault and the North Anatolian Shear Zone, in: Kuzucuoğlu, C., Çiner, A., Kazancı, N. (Eds.), Landscapes and Landforms of Turkey. Cham: Springer International Publishing, s. 481-494.

Topal, S. (2019a). Evaluation of relative tectonic activity along the Priene-Sazlı Fault (Söke Basin, southwest Anatolia): insights from geomorphic indices and drainage analysis. Journal of Mountain Science 16: 909-923.

Topal, S. (2019b). Karacasu Fayı́nın (GB Türkiye) göreceli tektonik aktivitesinin jeomorfik indislerle incelenmesi. Gümüşhane Üniversitesi Fen Bilimleri Enstitüsü Dergisi 9(1): 37-48.

Walcott, R. C. ve Summerfield, M. A. (2008). Scale dependence of hypsometric integrals: an analysis of southeast African basins. Geomorphology 96: 174-186.

Westaway, R. ve Arger, J. (2001). Kinematics of the Malatya-Ovacık Fault Zone. Geodin. Acta 14: 103-131.

Westaway, R., Demir, T. ve Seyrek, A. (2008). Geometry of the Turkey-Arabia and Africa-Arabia plate boundaries in the latest Miocene to Mid-Pliocene: the role of the Malatya-Ovacık Fault Zone in eastern Turkey. eEarth 3: 27-35.

Whipple, K. X ve Tucker, G. E. (1999). Dynamics of the stream-power river incision model: implications for height limits of mountain ranges, landscape response timescales, and research needs. Journal of Geophysical Research - Solid Earth 104: 17661-17674.

Whitney, B. B. ve Hengesh, J. V. (2015). Geomorphological evidence of neotectonic deformation in the Carnarvon Basin, Western Australia. Geomorphology 228: 579-596.

Whittaker, A. C. (2012). How do landscapes record tectonics and climate? Lithosphere 4(2): 160-164.
Williams, P. W. (1972). Morphpmetric analysis of polygonal karst in New Guinea. GSA Bulletin 83(3): 761-796.

Willett, S. D., Hovius, N., Brandon, M. T. ve Fisher, D. M. (2006). Tectonics, Climate and Landscape Evolution. Geological Society of America Special Paper 398. Penrose Conference Series, xi+434.

Wobus, C., Whipple, K. X., Kirby, E., Snyder, N., Johnson, J., Spyropolou, K., Crosby, B. ve Sheehan, D. (2006). Tectonics from topography: Procedures, promise, and pitfalls. Geol. Soc. Am. Spec. Pap. 398: 55-74.

Yazıcı, M., Zabcı, C., Sançar, T. ve Natal'in B. A. (2018a). The role of intraplate strike-slip faults in shaping the surrounding morphology: The Ovacık Fault (eastern Turkey) as a case study. Geomorphology 321: 129-145.

Yazıcı, M., Zabcı, C., Natal'in, B., Sançar, T. ve Akyüz, H. S. (2018b). Strike-slip deformation in a converging setting: insights from the Ovacık Fault (Anatolia, Turkey), European Geoscience Union General Assembly. EGU2018-1052.

Yıldırım, C. (2014). Relative tectonic activity assessment of the Tuzgölü Fault Zone; Central Anatolia, Turkey. Tectonophysics 630: 183-192.

Yıldırım, C., Sarıkaya, M. A. ve Çiner, A. (2016). Late Pleistocene intraplate extension of the Central Anatolian Plateau, Turkey: Inferences from cosmogenic exposure dating of alluvial fan, landslide, and moraine surfaces along the Ecemiş Fault Zone. Tectonics 35: 1446-1464.

Zabcı, C., Sançar, T., Tikhomirov, D., Ivy-Ochs, S., Vockenhuber, C., Friedrich, M.A., Yazıcı, M. ve Akçar, N. (2017). Cosmogenic $36 \mathrm{Cl}$ geochronology of offset terraces along the Ovacık Fault (Malatya-Ovacık Fault Zone, Eastern Turkey): implications for the intra-plate deformation of the Anatolian block. The International Conference on Astronomy and Geophysics, 330-334, Ulanbatar, Moğolistan 